\title{
Erratum to: The adapted augmented Lagrangian method: a new method for the resolution of the mechanical frictional contact problem
}

\author{
Philippe Bussetta • Daniel Marceau • \\ Jean-Philippe Ponthot
}

Published online: 4 October 2013

(C) Springer-Verlag Berlin Heidelberg 2013

Erratum to: Comput Mech (2012) 49:259-275

DOI 10.1007/s00466-011-0644-Z

In the original publication, the reference 31 has been published with incomplete information. However, the corrected reference should be read as below:

Rodríguez-Tembleque L, Buroni FC, Abascal R, Sáez A (2011) 3D frictional contact of anisotropic solids using BEM.

Eur J Mech A Solids 30(2):95-104.

The online version of the original article can be found under doi:10.1007/s00466-011-0644-z.

P. Bussetta $(\varangle) \cdot$ D. Marceau

Université du Québec à Chicoutimi,

555, boulevard de l'Université, Chicoutimi G7H 2B1, Canada

e-mail:P.Bussetta@ulg.ac.be

D. Marceau

e-mail: Daniel_Marceau@uqac.ca

J.-P. Ponthot

LTAS MN2L, Aerospace and Mechanical Engineering,

University of Liege, Building B52/3, Chemin des Chevreuils,

1, 4000 Liege, Belgium

e-mail: JP.Ponthot@ulg.ac.be 